\title{
Improving immunisation coverage in rural India: clustered randomised controlled evaluation of immunisation campaigns with and without incentives
}

\author{
Abhijit Vinayak Banerjee, Ford foundation international professor of economics, ${ }^{1}$ Esther Duflo, Abdul Latif \\ Jameel professor of poverty alleviation and development economics, ${ }^{1}$ Rachel Glennerster, executive \\ director, ${ }^{2}$ Dhruva Kothari, medical student ${ }^{3}$
}

${ }^{1}$ Department of Economics, Massachusetts Institute of Technology, 50 Memorial Drive, E52-391, Cambridge, MA 02142, USA

${ }^{2}$ Abdul Latif Jameel Poverty Action Lab, Massachusetts Institute of Technology, Cambridge, MA

${ }^{3} 630$ West 168th Street, Columbia University Physicians and Surgeons Mailbox \#67, New York, NY 10032, USA

Correspondence to: E Duflo eduflo@mit.edu

Cite this as: $B M J$ J 2010;340:c2220 doi:10.1136/bmj.c2220

\section{ABSTRACT}

Objective To assess the efficacy of modest non-financial incentives on immunisation rates in children aged 1-3 and to compare it with the effect of only improving the reliability of the supply of services.

Design Clustered randomised controlled study.

Setting Rural Rajasthan, India.

Participants 1640 children aged 1-3 at end point. Interventions 134 villages were randomised to one of three groups: a once monthly reliable immunisation camp (intervention A; 379 children from 30 villages); a once monthly reliable immunisation camp with small incentives (raw lentils and metal plates for completed immunisation; intervention B; 382 children from 30 villages), or control (no intervention, 860 children in 74 villages). Surveys were undertaken in randomly selected households at baseline and about 18 months after the interventions started (end point).

Main outcome measures Proportion of children aged 1-3 at the end point who were partially or fully immunised. Results Among children aged 1-3 in the end point survey, rates of full immunisation were 39\% (148/382, 95\% confidence interval $30 \%$ to $47 \%$ ) for intervention B villages (reliable immunisation with incentives), $18 \%$ $(68 / 379,11 \%$ to $23 \%)$ for intervention A villages (reliable immunisation without incentives), and 6\% (50/860, 3\% to $9 \%$ ) for control villages. The relative risk of complete immunisation for intervention B versus control was 6.7 (4.5 to 8.8) and for intervention B versus intervention A was 2.2 (1.5 to 2.8 ). Children in areas neighbouring intervention B villages were also more likely to be fully immunised than those from areas neighbouring intervention A villages (1.9, 1.1 to 2.8). The average cost per immunisation was $\$ 28$ (1102 rupees, about $£ 16$ or $€ 19)$ in intervention $A$ and $\$ 56$ (2202 rupees) in intervention B.

Conclusions Improving reliability of services improves immunisation rates, but the effect remains modest. Small incentives have large positive impacts on the uptake of immunisation services in resource poor areas and are more cost effective than purely improving supply. Trial registration IRSCTN87759937.

\section{INTRODUCTION}

Immunisation is a highly cost effective way of improving survival in children in developing countries. ${ }^{12}$ Every year throughout the world, however, an estimated 27 million children and 40 million pregnant women do not receive the basic package of immunisations (as defined by WHO and Unicef), and two to three million people die from diseases that can be prevented with vaccines. ${ }^{13}$ Immunisation rates are in part based on official statistics and might be over-reported. ${ }^{45}$ In India, immunisation services are offered free in public health facilities, but, despite rapid increases, the immunisation rate remains low in some areas. According to the National Family Health survey (NFHS-3), in India only $44 \%$ of children aged $1-2$ years have received the basic package. ${ }^{6}$ That drops to $22 \%$ in rural Rajasthan, the setting of the present study, and was less than $2 \%$ in our study area (a disadvantaged population in rural Udaipur) at baseline (according to a more detailed survey instrument than the NFHS-3, that was less likely to overestimate full immunisation rates). Understanding how to improve the uptake of immunisation is important, not only for existing vaccines but also to maximise the uptake of any new vaccine.

Reliable supply of free immunisation services and incentives to improve the demand for these services could improve immunisation rates. Previous studies have assessed the effectiveness of financial and nonfinancial incentives to encourage immunisation and other preventive health behaviours. Non-randomised studies of the measles campaign in Africa suggest that coupling the distribution of vaccines and bed nets increases ownership of bed nets by more than 40 percentage points, ${ }^{78}$ but the studies did not estimate the programme's impact on measles vaccination rates. In Nicaragua, attendance at an immunisation campaign increased from $77 \%$ to $94 \%$ when food incentives equivalent to about three to five days of wages were introduced to encourage vaccination in $1985 .{ }^{9}$ That study, however, was an observational study in which the treatments were sequential rather than contemporaneous. Conditional cash transfer programmes, 
popular in Latin American countries, have been effective in promoting the use of certain preventive healthcare services and have also had a positive impact on health outcomes for women and children. ${ }^{10-13}$ These programmes, however, did not have a large impact on immunisation rates. ${ }^{14}$ The lack of impact might be because of high initial immunisation rates in the areas where the programmes were carried out. Most conditional cash transfer programmes have been implemented in countries with existing adequate local health infrastructure so evaluations of their impact cannot shed light on the relative cost effectiveness of establishing incentive based interventions (versus improving quality of health infrastructure only) in more resource poor settings. ${ }^{10}$

We assessed the relative efficacy and cost effectiveness of improving the supply of infrastructure for immunisation only compared with improving supply and simultaneously increasing demand through the use of incentives. The study was a partnership between the Abdul Latif Jameel Poverty Action Lab (J-Pal) at the Massachusetts Institute of Technology and Seva Mandir, a non-governmental organisation in Udaipur district.

\section{METHODS}

We used a clustered randomised controlled trial to evaluate two interventions in rural Rajasthan, India. In one intervention (A), regular, well publicised immunisation clinics (referred to as "camps") were held, while in the second intervention (B), similar camps were held and parents were also offered small incentives to immunise their children. A third set of villages formed the control group. We used a cluster level design because individual level randomisation could have generated resentment against the non-governmental organisation.

\section{Selection and description of sample}

The main sample comprised 134 villages randomly selected from a Seva Mandir catchment area in Udaipur by using a computer generated random variable and over-sampling villages far away from a road. We also randomly selected one village within $6 \mathrm{~km}$ of each intervention village to measure potential spillover of the interventions.

Within each village, a household census was conducted, and 30 households containing children aged $0-5$ years were randomly selected with a random number generator to be part of the sample. The same households were surveyed again at the end point. The criterion for inclusion of a child in this study was to belong to a sampled household and to be aged 1-3 at the end point of the study (main sample) or to have been aged 0-6 months at baseline (baseline cohort).

As Seva Mandir works in poorer and more tribal villages, the villages selected are not representative of Udaipur in general but are representative of Seva Mandir's catchment area, an impoverished area where health status is poor. ${ }^{15}$ The public facilities serving these areas are characterised by high absenteeism: weekly visits during the year preceding the intervention showed that $45 \%$ of the health staff in charge of immunisations (auxiliary nurse midwives) were absent from their village level health centre (and could not be found anywhere in the village) on any given workday, and there was no predictable pattern to their absence. ${ }^{11}$

\section{Interventions}

In this study children received the WHO/Unicef extended package of immunisation, provided by the Indian government. This includes one dose of BCG vaccine, three doses of DPT (diphtheria-pertussis, tetanus) vaccine, three doses of oral polio vaccine, and one dose of measles vaccine. ${ }^{16}$ A child should be fully immunised (that is, have received all the vaccines in the extended package) by the age of 1 year.

Given that a full immunisation course requires at least five visits to a public health facility, the unreliability of the auxiliary nurse midwives might deter families from taking their children to the centre to complete the full immunisation schedule. Therefore, intervention A ("immunisation camps") focused on establishing regular availability of immunisation services. It consisted of a mobile immunisation team, including a nurse and assistant (both hired by Seva Mandir), who conducted monthly immunisation camps in the villages. The nurse and assistant held the camp on a fixed date every month at a fixed time (11 am to $2 \mathrm{pm})$. The presence of the nurse and assistant was verified by the requirement of timed and dated pictures of them in the villages and by regular monitoring. Review of records showed that of 1336 planned camps, 95\% (1269) took place. In addition, in each village a social worker was responsible for identifying children, informing mothers about the availability of the immunisation camps, and educating them about the benefits of immunisation. Seva Mandir has been active in the area for over 50 years and is trusted in villages. While this programme was new, and Seva Mandir had not been engaged in any effort to provide immunisation before, the health unit of the organisation had been conducting several programmes in these villages or in neighbouring villages, most notably an effective programme of training traditional birth attendants for delivery. Many villages also already had health social workers, responsible for general health advice, information on prenatal and other preventive care, referral to health centres, and help with the DOT (directly observed therapy) programme. The organisation thus benefits from a high level of trust among villagers, which might have ameliorated issues of mistrust that surround immunisation programmes in India. ${ }^{17}$

Intervention B used the same infrastructure as intervention A but in addition offered parents $1 \mathrm{~kg}$ of raw lentils per immunisation administered and a set of thalis (metal plates used for meals) on completion of a child's full immunisation. The value of the lentils was about 40 rupees (about $\$ 1$ ), equivalent to three quarters of one day's wage, and the value of the thalis was about 75 rupees. Seva Mandir decided to provide lentils, rather than cash, as this was useful to the family and also 
immediate had nutritional value. The amount roughly corresponds to the opportunity cost of time for the mother. The thalis were chosen as a tangible sign of achievement, while also being of immediate use.

At the first immunisation, every child was given an official immunisation card indicating their name, the name of their parent/s, and the date and type of each immunisation performed. The nurse also kept a detailed logbook. Following standard guidelines, when a child arrived at a camp without an immunisation card and it could not be ascertained whether he or she had received a given immunisation, the child was immunised. ${ }^{18}$

\section{Study and evaluation design}

We evaluated the impact of the interventions using a clustered randomised control trial. Using the random number generator in the statistical package Stata (version 9), and after stratification by geographical block (the administrative unit above the village), one author (ED) randomly selected 30 of the 134 study villages to receive intervention $\mathrm{A}$ and 30 to receive intervention B. The 74 remaining villages were control villages and received no additional intervention. Naturally, given the context and the intervention, the allocation of villages to treatment or control was not blind. In most control villages, a Seva Mandir health worker was present and encouraging uptake of preventive services, including immunisation, was part of their mission. Villagers were to obtain immunisation in the closest health centre. In all villages, the government nurse continued to provide immunisation services for the duration of the study. When a camp was established in a village, any non-immunised child younger than 5 , from any village, was eligible for immunisation in the camp. All children younger than 2 were eligible for the lentils in intervention B camps, irrespective of the village they came from. (Villages from all three treatment groups were sufficiently far from each other (over $20 \mathrm{~km}$ ) so we expected no contamination between the villages.) Children who began the immunisation course before turning 2 remained eligible for the incentives until the completion of the immunisation course. Therefore children included in the study sample were aged 1-3 at the end point survey.

\section{Data sources}

Our primary outcome was the receipt of all or part of the extended package of immunisation. Most households in the areas did not have immunisation cards so we ascertained the immunisation rate during interviews with the mother. Mothers were surveyed about the immunisation status of all children aged under 7 at the end point and about her immunisation status during her pregnancy with each child.

We developed our survey instrument to elicit accurate reporting of immunisation status, regardless of where the immunisation was obtained (camp, health centres, private doctor). Because a parent might confuse immunisation with other injections (injection of antibiotics is common in India) and might not realise the difference between different vaccinations, the instrument asked in detail about each injection received by the child, including whether it was administered to cure a sickness, in which facility it was administered, and where on the body it was injected. In addition, at the end of the survey, the field officer examined the child to ascertain whether they had the distinctive scar left by the BCG vaccine. If the family had a vaccination card for the child researchers also recorded the information on the card.

Self report can be influenced by recall bias (mothers, who are often illiterate, might not remember) and potentially by social desirability bias, which might be affected by their intervention group. We carried out several validation exercises in which we compared the self reports with the BCG scar, the immunisation card (available for 343 children), and a sample of children from intervention villages. The immunisation camp records were matched with the survey data. BCG self report seemed to be accurate (see appendix 1 on bmj.com). Immunisation status elicited from the survey instrument corresponded to within one injection of the status indicated on the card 79\% of the time and to within one injection of the status indicated in the logbook $74 \%$ of the time. The mis-measurement was not correlated with the treatment status or the number of immunisations reported and was not systematically over-reported or under-reported and should therefore increase noise but not necessarily introduce bias (as measurement error is the dependent variable and is not differential in different treatment groups).

While self reports of immunisation from mothers who do not have an immunisation card is not perfect, a meta-analysis of several validation studies has shown that they are generally of acceptable quality and that they represent "the best available independent measure of DPT3 coverage." 4

Nevertheless, to verify that the results were not biased by the use of self reported data, we carried out two additional analyses: an analysis of the presence of BCG scar (observed by the field officer at the end of the mother's interview) and an analysis based on the administrative data maintained in intervention $\mathrm{A}$ and intervention $\mathrm{B}$ villages. For these children, a complete computerised record of immunisation received in the camp and elsewhere is maintained. This allows a comparison of intervention $A$ and $B$ villages for children who have received at least one immunisation in the camp. For this analysis, we also focused on children aged 1-3.

The baseline survey took place between June 2004 and February 2005 and covered all children aged 0-5 in the sample households. The intervention started in each geographical block after the baseline investigations. The end point survey took place between July 2006 and February 2007, about 18 months after the interventions started in a particular village. It used the same survey instruments and covered all children age 07 in the same households to identify eligible children (13 at end point, or 0-6 months at end point). Both surveys were blind: interviewers did not know which villages belonged to which intervention (or control) group. 


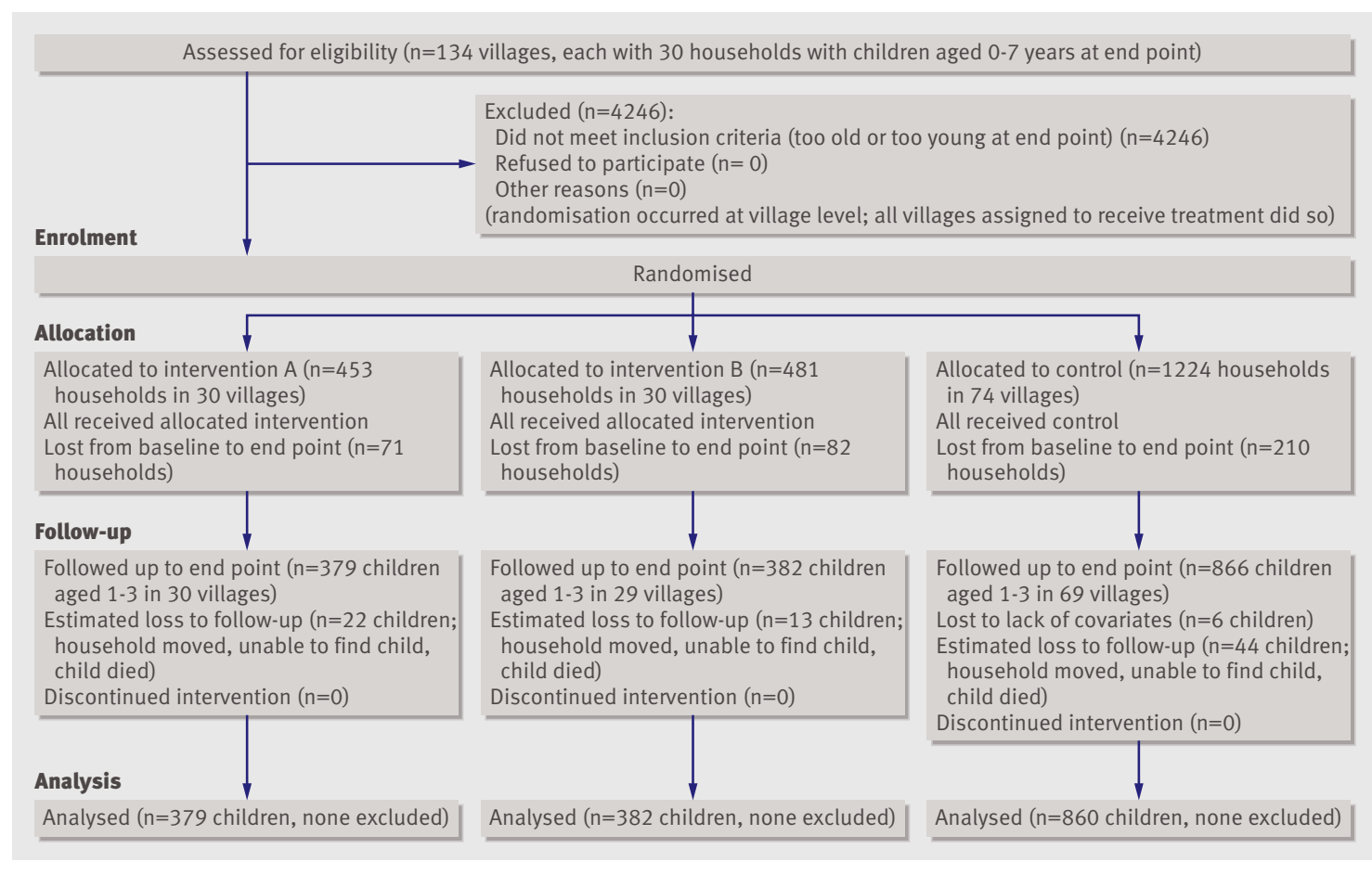

Fig 1 | Flow of participants through study

Data entry, cleaning, and validation were completed in September 2007 and analysis and report write up took place between October 2007 and May 2008. The paper was revised a first time between September 2009 and November 2009 and a second time in March 2010.

\section{End points}

In the household sample, our main analysis focused on children aged 1- 3 at the end point (that is, eligible and old enough to be fully immunised). The outcomes include the probability of receiving at least one immunisation (excluding oral polio vaccine, which almost all children have received and therefore does not affect the statistics); the presence of the BCG scar; the number of immunisations received; and the probability of receiving the complete extended package of immunisation.

We also analysed the administrative data collected in the camp: the outcomes were the number of immunisations received by children who received at least one immunisation in the camp, and the probability of receiving all the vaccines in the extended package of immunisation.

Complementary analysis reports the impact of the interventions on neighbouring villages. We report the probability of being immunised in villages neighbouring intervention $\mathrm{A}$ and intervention $\mathrm{B}$ camps, differences between these two groups of neighbouring villages and the control group, and relative risks.

\section{Costs}

We carried out a cost effectiveness analysis of both interventions (see appendix 2 on bmj.com for details).

\section{Statistical analysis}

Taking into account correlation of the end point within a village and clustering of the treatment at that level (a intracluster correlation of 0.25 was assumed based on a preliminary survey) and given a baseline immunisation rate of $2 \%$ in the control group, we determined that a sample of 30 villages per treatment arm, with a random sample of 30 households per village (assuming about 1.4 children aged 1-3 years surveyed in each household), was sufficient to obtain $80 \%$ power for a $5 \%$ level test of a difference of at least five percentage points in the probability of being fully immunised between any two groups (treatment A, treatment B, and comparison). The larger control group increases power.

We used intention to treat analysis - that is, all households were analysed with the assumption that they remained in the treatment group to which they were initially assigned. For the binary variables, we report proportion in each group, difference in proportions across groups, and relative risks. For the count variables (number of immunisation), we report values in the treatment group, difference across groups, and relative risks. The analysis adjusts for clustering at the village and the family level. For the difference in proportion, we used a multilevel mixed effect linear model of the probability of being immunised on the treatment indicator, with a hierarchical error structure that allows cluster level heterogeneity (random effect) at the village and at the family level. For the relative risk, we used a multilevel mixed effect Poisson model with the same hierarchical error structure. We did not include any control variables. In all the analyses we used Stata version 10. 
Table 1|Baseline characteristics by allocated group*. Figures are percentages of children unless stated otherwise

\begin{tabular}{|c|c|c|c|}
\hline & Control group & Treatment A & Treatment B \\
\hline Mean age (months) & $10.2(9.2$ to 11.3$)$ & $10.4(8.8$ to 12.0$)$ & $\begin{array}{c}11.06(9.72 \text { to } \\
12.40)\end{array}$ \\
\hline Mean household size (No of people) & 6.7 (6.5 to 7.0$)$ & $6.7(6.3$ to 7.1$)$ & $6.74(6.46$ to 7.03$)$ \\
\hline Male & 0.5 (0.5 to 0.6$)$ & 0.5 (0.4 to 0.6$)$ & 0.50 (0.44 to 0.57$)$ \\
\hline $\begin{array}{l}\text { Member of scheduled castes/scheduled } \\
\text { tribes (disadvantaged group) }\end{array}$ & 0.9 (0.8 to 1.0$)$ & 0.9 (0.8 to 1.0$)$ & 0.96 (0.8 to 1.02$)$ \\
\hline Literate head of household & $0.4(0.3$ to 0.4$)$ & $0.4(0.3$ to 0.5$)$ & $0.37(0.27$ to 0.47$)$ \\
\hline Monthly household income $†$ & $\begin{array}{l}2858.70(2433.17 \\
\text { to } 3284.23)\end{array}$ & $\begin{array}{c}3196.57(2743.95 \\
\text { to } 3649.18)\end{array}$ & $\begin{array}{c}2729.09(2374.79 \\
\text { to } 3083.39)\end{array}$ \\
\hline Land size owned by family (in bighas $\ddagger$ ) & $3.9(3.5$ to 4.3$)$ & $4.0(3.5$ to 4.5$)$ & $3.51(2.98$ to 4.04$)$ \\
\hline Below poverty line & $0.5(0.5$ to 0.6$)$ & $0.5(0.4$ to 0.6$)$ & $0.50(0.42$ to 0.59$)$ \\
\hline No of rooms in house & 2.0 (1.8 to 2.2$)$ & 2.1 (1.8 to 2.4 ) & 1.90 (1.74 to 2.06$)$ \\
\hline House has electricity & $0.2(0.1$ to 0.2$)$ & $0.2(0.1$ to 0.3$)$ & $0.06(0$ to 0.12$)$ \\
\hline Treats water & 1.1 (1.1 to 1.2$)$ & 1.1 (1.0 to 1.1$)$ & 1.08 (1.03 to 1.12$)$ \\
\hline No of immunisations & $0.6(0.5$ to 0.8$)$ & $0.8(0.5$ to 1.1$)$ & $0.45(0.25$ to 0.65$)$ \\
\hline Completely immunised & 0.01 (0 to 0.01$)$ & $0.02(0$ to 0.04$)$ & $0.00(0$ to 0.02$)$ \\
\hline At least one injection & 0.3 (0.3 to 0.4$)$ & $0.4(0.3$ to 0.5$)$ & $0.30(0.19$ to 0.4$)$ \\
\hline
\end{tabular}

${ }^{*} \mathrm{~A}=$ reliable immunisation camps, 30 villages; $\mathrm{B}=$ reliable immunisation camps with incentives, 30 villages; control=no treatment, 74 villages.

tIn rupees (1000 rupees $=$ about $£ 15, € 17, \$ 23)$.

$\ddagger$ Generally $<1$ acre $(0.4$ hectare). adverse events (severe reaction to immunisation) reported in either intervention groups.

The difference between intervention $B$ and intervention A was more marked for full immunisation than for the number of immunisations received and disappeared for the probability of receiving at least one injection. Specifically, $78 \%(70 \%$ to $85 \%)$ of children in intervention A villages received at least one injection compared with $74 \%$ (67\% to $82 \%)$ of children in intervention B villages. Similarly, 50\% (41\% to 59\%) of children in intervention A villages and $50 \%$ (41\% to $59 \%$ ) of children in intervention B villages had a BCG scar (v $28 \%(21 \%$ to $36 \%)$ in control villages) (fig 3), showing that the impact of the incentive was mainly to reduce the number of children dropping out after three injections. Over half $(52 \%, 43 \%$ to $62 \%)$ of children who were reported as receiving at least one injection in intervention $\mathrm{B}$ villages were completely immunised compared with $23 \%(15 \%$ to $32 \%)$ in intervention A.

The analysis of the logbooks confirms these results. Of the children who received at least one injection in the camps, $485 / 700(67 \%, 59 \%$ to $74 \%)$ were fully immunised in intervention B and 197/407 (48\%, 38\% to $59 \%$ ) were fully immunised in intervention $\mathrm{A}$. The relative risk of being completely immunised in intervention $\mathrm{B}$ compared with intervention $\mathrm{A}$ for children who received at least one injection was 1.4 (1.1 to 1.7). The propensity for children to drop out before completing the full course, particularly in intervention A villages, was not because the camps became less popular over time: children who received their first immunisation later received on average the same number of immunisations as children who received their first immunisation earlier.

\section{Impact on neighbouring villages}

Table 3 shows immunisation rates in villages neighbouring the intervention villages. In villages within a few kilometres of an intervention B camp, 61/302 children $(20 \%, 10 \%$ to $31 \%)$ were completely immunised compared with $36 / 265$ children $(11 \%, 5 \%$ to $16 \%)$ in villages bordering an intervention A camp. These confidence intervals overlap, but the relative risk is significantly greater than one. The relative risk of being completely immunised for villages neighbouring inter-

\section{Primary end point: impact on immunisation in treatment village}

The highest rate of full immunisation was observed for intervention $\mathrm{B}$ (table 2, fig 2). In intervention B villages, 148/382 (mean 39\%, 95\% confidence interval $30 \%$ to $47 \%$ ) children were completely immunised compared with $68 / 379(18 \%, 11 \%$ to $23 \%)$ in intervention A villages and 50/860 (6\%,3\% to $9 \%)$ in control villages (fig 2). The relative risk of being completely immunised was 3.1 (2.0 to 4.2 ) for intervention A versus control, 6.7 (4.5 to 8.8) for intervention $\mathrm{B}$ versus control, and 2.2 for intervention $\mathrm{B}$ versus intervention $\mathrm{A}$ (1.5 to 2.8). Compared with the control group, immunisation rates more than doubled in intervention A villages and increased by more than six times in the intervention B villages. There were no

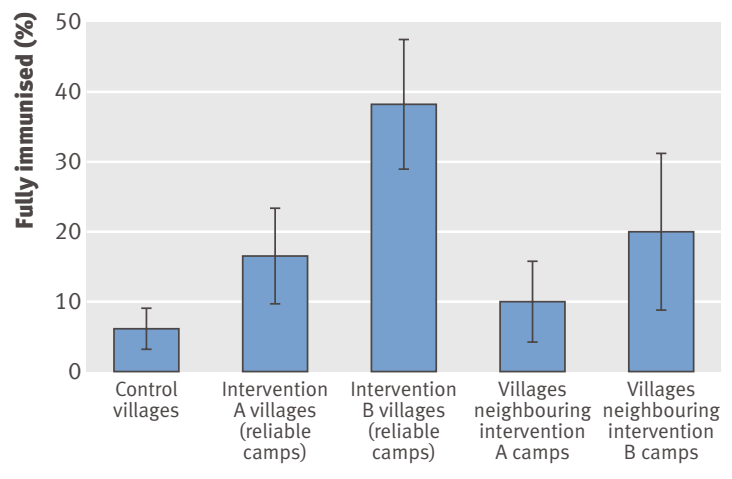

Fig 2 | Percentage of children aged 1-3 years fully immunised by treatment status 
Table 2 | Effects of group allocation (A=immunisation, B=immunisation plus incentive). Numbers are in absolute values

\begin{tabular}{|c|c|c|c|c|c|c|c|c|c|}
\hline & \multicolumn{3}{|c|}{ Mean $(95 \% \mathrm{Cl})$} & \multicolumn{3}{|c|}{ Difference* $(95 \% \mathrm{Cl})$} & \multicolumn{3}{|c|}{ Relative risk† $(95 \% \mathrm{Cl})$} \\
\hline & Control & A & B & A-control & B-control & B-A & A v control & B $v$ control & $\mathrm{B} v \mathrm{~A}$ \\
\hline \multicolumn{10}{|c|}{ End point cohort (aged 1-3 years) } \\
\hline No in group & 860 & 379 & 382 & - & - & - & - & - & - \\
\hline No of immunisations & $\begin{array}{c}1.20 \\
\text { (0.94 to } 1.46)\end{array}$ & $\begin{array}{c}2.35 \\
\text { (1.99 to } 2.71)\end{array}$ & $\begin{array}{c}2.85 \\
\text { (2.44 to } 3.25)\end{array}$ & $\begin{array}{c}1.15 \\
\text { (0.95 to } 1.35)\end{array}$ & $\begin{array}{c}1.70 \\
\text { (1.48 to } 1.92)\end{array}$ & $\begin{array}{c}0.55 \\
(0.26 \text { to } 0.83)\end{array}$ & $\begin{array}{c}2.14 \\
\text { (1.84 to } 2.44)\end{array}$ & $\begin{array}{c}2.66 \\
\text { (2.28 to } 3.05)\end{array}$ & $\begin{array}{c}1.22 \\
\text { (1.08 to } 1.36)\end{array}$ \\
\hline$\geq 1$ immunisation & $\begin{array}{c}0.49 \\
\text { (0.40 to } 0.57)\end{array}$ & $\begin{array}{c}0.78 \\
(0.70 \text { to } 0.85)\end{array}$ & $\begin{array}{c}0.74 \\
(0.67 \text { to } 0.82)\end{array}$ & $\begin{array}{c}0.29 \\
\text { (0.23 to } 0.35)\end{array}$ & $\begin{array}{c}0.26 \\
(0.20 \text { to } 0.33)\end{array}$ & $\begin{array}{c}-0.03 \\
(-0.09 \text { to } 0.04)\end{array}$ & $\begin{array}{c}1.59 \\
\text { (1.35 to } 1.83 \text { ) }\end{array}$ & $\begin{array}{c}1.52 \\
(1.29 \text { to } 1.75)\end{array}$ & $\begin{array}{c}0.96 \\
\text { (0.80 to 1.11) }\end{array}$ \\
\hline Has BCG scarf & $\begin{array}{c}0.28 \\
\text { (0.21 to } 0.36)\end{array}$ & $\begin{array}{c}0.50 \\
(0.41 \text { to } 0.59)\end{array}$ & $\begin{array}{c}0.50 \\
(0.41 \text { to } 0.59)\end{array}$ & $\begin{array}{c}0.22 \\
(0.15 \text { to } 0.28)\end{array}$ & $\begin{array}{c}0.22 \\
(0.15 \text { to } 0.28)\end{array}$ & $\begin{array}{c}0.00 \\
(-0.08 \text { to } 0.08)\end{array}$ & $\begin{array}{c}1.76 \\
\text { (1.41 to } 2.12)\end{array}$ & $\begin{array}{c}1.76 \\
\text { (1.41 to } 2.12)\end{array}$ & $\begin{array}{c}1.00 \\
(0.79 \text { to } 1.21)\end{array}$ \\
\hline Completely immunised & $\begin{array}{c}0.06 \\
\text { (0.03 to 0.09) }\end{array}$ & $\begin{array}{c}0.18 \\
(0.11 \text { to } 0.25)\end{array}$ & $\begin{array}{c}0.39 \\
(0.30 \text { to } 0.47)\end{array}$ & $\begin{array}{c}0.13 \\
\text { (0.09 to } 0.16)\end{array}$ & $\begin{array}{c}0.34 \\
(0.30 \text { to } 0.38)\end{array}$ & $\begin{array}{c}0.21 \\
(0.15 \text { to } 0.28)\end{array}$ & $\begin{array}{c}3.09 \\
\text { (1.96 to } 4.21)\end{array}$ & $\begin{array}{c}6.66 \\
\text { (4.53 to } 8.80)\end{array}$ & $\begin{array}{c}2.16 \\
\text { (1.54 to } 2.78)\end{array}$ \\
\hline \multicolumn{10}{|c|}{ Logbook cohort (aged 1-3 years) } \\
\hline No in group & - & 407 & 725 & - & - & - & - & - & - \\
\hline Total No of immunisations & - & $\begin{array}{c}3.70 \\
\text { (3.39 to 4.01) }\end{array}$ & $\begin{array}{c}4.18 \\
\text { (3.99 to } 4.37 \text { ) }\end{array}$ & - & - & $\begin{array}{c}0.59 \\
(0.25 \text { to } 0.93) \\
\end{array}$ & - & 一 & $\begin{array}{c}1.15 \\
\text { (1.05 to } 1.25)\end{array}$ \\
\hline Completely immunised & - & $\begin{array}{c}0.48 \\
(0.38 \text { to } 0.59)\end{array}$ & $\begin{array}{c}0.67 \\
(0.59 \text { to } 0.74)\end{array}$ & - & - & $\begin{array}{c}0.22 \\
(0.10 \text { to } 0.33)\end{array}$ & - & - & $\begin{array}{c}1.43 \\
\text { (1.12 to } 1.73)\end{array}$ \\
\hline
\end{tabular}

*Estimated by fitting multilevel mixed effect linear model, with clustering at hamlet and household level.

†Estimated by fitting multilevel mixed effect Poisson regression, with clustering at hamlet and household level.

¥For analysis with BCG scar as outcome, there were 790 observations in control group, 334 in treatment A group, and 336 in treatment B group.

vention $\mathrm{B}$ camps versus those neighbouring intervention A camps was 1.9 (1.1 to 2.8) (table 3).

This analysis is confirmed in the logbook data, where results are more precise. In villages within a few kilometres of an intervention B camp, 452/700 children who received at least one immunisation (65\%, $58 \%$ to $72 \%)$ were completely immunised compared with $69 / 208$ children $(33 \%, 23 \%$ to $44 \%)$ in villages bordering an intervention A camp.

\section{Costs}

The average cost to Seva Mandir of fully immunising a child was $\$ 27.94$ (1102 rupees, about $£ 16$ or $€ 19$ ) in the reliable camp with incentives and $\$ 55.83$ (2202 rupees) in the reliable camp without incentives (see appendix 2 on bmj.com for further details). The difference comes from the fact that camps had to be open from 11 am to $2 \mathrm{pm}$, regardless of the number of children present. Thus, the higher average number of children in the camps with incentives spread the daily fixed cost (mainly, the salary of the nurse and assistant) over more children. The marginal cost of an extra child being fully immunised with and without incentive in a given camp is, respectively, $\$ 6.60$ and $\$ 1.30$. The salaries of the nurse and assistant represent about half of the cost of the camp without incentives. Monitoring that the camps are regularly held is another important part of the cost, which is necessary in light of high absenteeism. ${ }^{14}$ When we calculated the cost that would be incurred by a government able to use an existing health infrastructure, the average cost of fully immunising a child was estimated at $\$ 25.18$ in camps without incentives and \$17.35 in camps with incentives.

\section{DISCUSSION}

\section{Summary of results}

This randomised controlled study of immunisation camps shows that offering modest incentives to families in resource poor settings can significantly increase uptake of immunisation services, when reliable services are available. In our study, reliable camps with incentives achieved significantly higher rates of full immunisation for children aged 1-3 compared with control areas where no camps were made available and compared with reliable camps without incentives. While control villages had a full immunisation rate of nearly $6 \%$, villages in which a reliable camp was held showed rates of around $18 \%$, and adding the incentive pushed rates to nearly $40 \%$, a significant increase. The rate achieved with incentives represents a more than sixfold increase over the rate in control villages, in a particularly poor and hard to reach population. It is, however, still too low to achieve herd immunity.

Surprisingly, despite that fact that the family received a set of plates for the last immunisation, the biggest increase between intervention $A$ and intervention $B$ villages was for the third and fourth immunisation. This might indicate that parents are more sensitive to the fact that there is an incentive than to the level of the incentive, a finding consistent with the results that in condi-

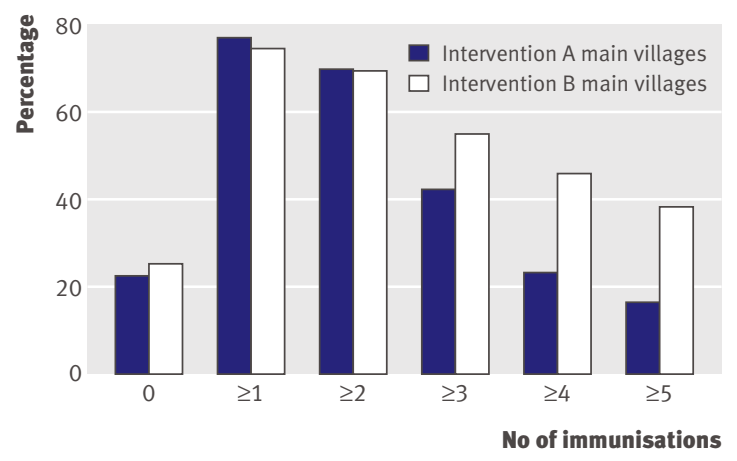

Fig $3 \mid$ Number of immunisations received by children aged 1-3 years 
Table 3 Effects of treatment in villages adjacent to intervention or control villages ( $A=$ immunisation, $B=$ immunisation plus incentive)

\begin{tabular}{|c|c|c|c|c|c|c|c|c|c|}
\hline & \multicolumn{3}{|c|}{ Mean in group $(95 \% \mathrm{Cl})$} & \multicolumn{3}{|c|}{ 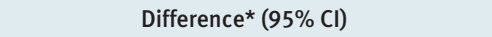 } & \multicolumn{3}{|c|}{ Relative risk† $(95 \% \mathrm{Cl})$} \\
\hline & Control & Treat A & B & A-control & B-control & B-A & A $v$ control & B $v$ control & $B v A$ \\
\hline \multicolumn{10}{|c|}{ End point cohort (aged 1-3 years) } \\
\hline No in group & 860 & 265 & 302 & - & - & - & - & - & - \\
\hline No of immunisations & $\begin{array}{c}1.20 \\
\text { (0.94 to } 1.46)\end{array}$ & $\begin{array}{c}1.41 \\
\text { (0.94 to } 1.88)\end{array}$ & $\begin{array}{c}1.70 \\
\text { (1.18 to } 2.22)\end{array}$ & $\begin{array}{c}0.23 \\
(0.00 \text { to } 0.46)\end{array}$ & $\begin{array}{c}0.58 \\
(0.35 \text { to } 0.82)\end{array}$ & $\begin{array}{c}0.36 \\
(0.02 \text { to } 0.69)\end{array}$ & $\begin{array}{c}1.18 \\
\text { (0.92 to } 1.43)\end{array}$ & $\begin{array}{c}1.48 \\
\text { (1.18 to } 1.77)\end{array}$ & $\begin{array}{c}1.26 \\
\text { (0.93 to } 1.60)\end{array}$ \\
\hline$\geq 1$ immunisation & $\begin{array}{c}0.49 \\
(0.40 \text { to } 0.57)\end{array}$ & $\begin{array}{c}0.49 \\
(0.34 \text { to } 0.64)\end{array}$ & $\begin{array}{c}0.51 \\
(0.39 \text { to } 0.63)\end{array}$ & $\begin{array}{c}0.01 \\
(-0.06 \text { to } 0.09)\end{array}$ & $\begin{array}{c}0.05 \\
(-0.02 \text { to } 0.12)\end{array}$ & $\begin{array}{c}0.03 \\
(-0.06 \text { to } 0.12)\end{array}$ & $\begin{array}{c}1.00 \\
(0.80 \text { to } 1.19)\end{array}$ & $\begin{array}{c}1.05 \\
(0.86 \text { to } 1.24)\end{array}$ & $\begin{array}{c}1.05 \\
\text { (0.81 to } 1.30)\end{array}$ \\
\hline Has BCG scarł & $\begin{array}{c}0.28 \\
(0.21 \text { to } 0.36)\end{array}$ & $\begin{array}{c}0.28 \\
(0.16 \text { to } 0.41)\end{array}$ & $\begin{array}{c}0.30 \\
(0.18 \text { to } 0.41)\end{array}$ & $\begin{array}{c}0.01 \\
(-0.06 \text { to } 0.08)\end{array}$ & $\begin{array}{c}0.03 \\
(-0.04 \text { to } 0.10)\end{array}$ & $\begin{array}{c}0.02 \\
(-0.07 \text { to } 0.10)\end{array}$ & $\begin{array}{c}1.00 \\
(0.73 \text { to } 1.28)\end{array}$ & $\begin{array}{c}1.05 \\
(0.78 \text { to } 1.32)\end{array}$ & $\begin{array}{c}1.05 \\
\text { (0.70 to } 1.39)\end{array}$ \\
\hline Completely immunised & $\begin{array}{c}0.06 \\
(0.03 \text { to } 0.09)\end{array}$ & $\begin{array}{c}0.11 \\
(0.05 \text { to } 0.16)\end{array}$ & $\begin{array}{c}0.20 \\
(0.10 \text { to } 0.31)\end{array}$ & $\begin{array}{c}0.05 \\
(0.01 \text { to } 0.09)\end{array}$ & $\begin{array}{c}0.16 \\
(0.12 \text { to } 0.20)\end{array}$ & $\begin{array}{c}0.11 \\
(0.05 \text { to } 0.18)\end{array}$ & $\begin{array}{c}1.83 \\
\text { (0.93 to } 2.73)\end{array}$ & $\begin{array}{c}3.47 \\
(2.18 \text { to } 4.77)\end{array}$ & $\begin{array}{c}1.91 \\
(1.06 \text { to } 2.77)\end{array}$ \\
\hline \multicolumn{10}{|c|}{ Logbook cohort (aged 1-3 years) } \\
\hline No in group & - & 208 & 700 & - & - & - & - & - & - \\
\hline Total No of immunisations & - & $\begin{array}{c}3.23 \\
(2.91 \text { to } 3.55)\end{array}$ & $\begin{array}{c}4.15 \\
\text { (3.95 to } 4.35)\end{array}$ & - & - & $\begin{array}{c}0.92 \\
(0.50 \text { to } 1.35)\end{array}$ & - & - & $\begin{array}{c}1.28 \\
\text { (1.14 to } 1.42)\end{array}$ \\
\hline Completely immunised & - & $\begin{array}{c}0.33 \\
(0.23 \text { to } 0.44)\end{array}$ & $\begin{array}{c}0.65 \\
(0.58 \text { to } 0.72)\end{array}$ & - & - & $\begin{array}{c}0.30 \\
(0.15 \text { to } 0.45)\end{array}$ & - & - & $\begin{array}{c}1.91 \\
\text { (1.36 to } 2.45)\end{array}$ \\
\hline
\end{tabular}

*Estimated by fitting multilevel mixed effect linear model, with clustering at village and household level.

†Estimated by fitting multilevel mixed effect Poisson regression, with clustering at village and household level.

fFor the analysis with BCG scar as outcome, there were 790 observations in control group, 239 in treatment A group, and 252 in treatment B group.

tional cash transfer programme, the size of the transfer does not seem to matter beyond the fact that there is a positive transfer, ${ }^{1920}$ and suggests that larger incentives might not increase the immunisation rate much beyond what was found here. Moreover, while a camp without incentives increased immunisation rates only in the village where it took place, camps with incentives also increased rates in neighbouring villages.

\section{Comparison with other studies}

Several previous studies have shown that uptake of preventive behaviours is sensitive to small incentives or small costs, suggesting that incentives can play a role in promoting preventive health services. ${ }^{9192122}$ Other researchers have suggested that in resource poor settings, ensuring a reliable supply of health services and educating parents about the benefits of preventive care are more important than providing incentives. ${ }^{923}$ Our findings contrast with those of a study in Timor Leste, which found that food incentives did not increase the completion of tuberculosis treatment. ${ }^{24}$ This difference might be attributable to various factors: the frequency of the treatment (vaccines versus daily treatment); the fact that adults were targeted in the tuberculosis intervention; the relatively high initial compliance rate; and the difference in demand for treatment and prevention. More studies are needed to understand in what conditions incentives for parents or patients have a positive impact.

\section{Limitations of study}

We relied in part on self reported data on immunisation, though the results were robust when we used the BCG scar or the immunisation reported in the logbook as outcomes. The study was not blind from the point of view of the villagers, who might have been motivated to attend the camp to ensure that Seva Mandir would not cancel the programme. The study was also conducted in an environment with low density where initial immunisation rates were extremely low. In areas where initial immunisation rates are higher, similar interventions might not produce as dramatic an increase. On the other hand, the impacts might be much higher and the costs much lower in more densely populated regions. Finally, we could look only at the joint effect of improving supply and incentivising demand. Because it would have been impossible to administer in practice, we could not introduce an incentive programme without simultaneously making the supply more reliable.

\section{Policy implications}

The magnitude of our results shows that, in this setting, holding regular immunisation camps combined with incentives improves immunisation rates, even though the rate of full immunisation remained low. Moreover, providing incentives and improving the supply of services was also more cost effective than improving the supply of services alone. The cost of immunising with incentive (around \$17.35) is higher than the cost currently in the Indian budget (about $\$ 4$ per immunisation, according to the healthcare budget ${ }^{25}$ ), but it is of an order of magnitude comparable with the payment from the Global Alliance for Vaccines and Immunisation (GAVI) to member countries of $\$ 20$ per "extra child" who would not have been immunised otherwise. This is a relevant comparison as these kinds of programme would target "difficult to reach" children who are not already immunised under India's standard programme. A review of interventions to improve immunisation found that the cost of most interventions is about $\$ 10-20$ per newly immunised child. ${ }^{26}$ Moreover, while the lentils represented a cost to Seva Mandir, their distribution could have led to improved nutrition for the family in an environment where malnutrition and anaemia are endemic, and it is not clear they should be considered as a cost. 


\section{WHAT IS ALREADY KNOWN ON THIS TOPIC}

Financial incentives, such as in conditional cash transfer programmes, can be effective in promoting the use of certain preventive healthcare services

In settings with reliable immunisation services and a high pre-existing immunisation rate such programmes have little impact on immunisation

\section{WHAT THIS STUDY ADDS}

In a setting with a low immunisation rate (under $6 \%$ ), improving the reliability of services modestly improved uptake of immunisation

Small non-financial incentives, combined with improved reliability, had large positive impacts on the uptake of immunisation and were more cost effective

One implication of the increased immunisation rates in the villages with camps with incentives (and in the surrounding villages) is that they were busier than those without incentives. Inspection of the logbook showed that for any given camp, each day an average of 4.5 immunisations were given without incentives and 13.4 with incentives.

Interpretation, unanswered questions, and future research Our results also suggest reasons that immunisation has not been more widely embraced in developing countries. Previous work has emphasised the need to strengthen health systems to achieve the millennium development goals. $^{27}$ Our results suggest that to achieve this strengthening, improving the supply alone might not be enough: even a fully reliable supply system has a relatively modest effect on uptake of immunisation. In intervention $\mathrm{A}$, even when access was good and a social worker constantly reminded parents of the benefits of immunisation, more than $80 \%$ did not get their children fully immunised. Nevertheless, more than $75 \%$ obtained the first injection without the incentive and stopped attending the camps only after two or three injections. This shows that the parents do not have strong objections or fears about immunisation, but that they are not persuaded enough about its benefits to overcome the natural tendency to delay a slightly costly activity (immunisation is free, but it takes some time and effort to go to the centre and get the child immunised, and the child might have a fever afterwards). This fits the findings of sociological research in India, where nurses describe parents forgetting to bring their children to the immunisation day, and where they are particularly careful to manage even benign side effects of immunisation to avoid discouraging parents from coming back. ${ }^{5}$ It also explains the tendency for children not to complete the whole course of immunisation. Providing the lentils helps to overcome this procrastination because the lentils make the occasion a small "plus" rather than a small "minus." Thus, in the case of preventive care, small barriers might turn out to have large implications. Finding effective ways to overcome small barriers might hold the key to large improvements in immunisation rates and uptake of other preventive health behaviours. In the case of immunisation, small incentives coupled with regular delivery of services seem to have the potential to play this role.

While we primarily examined the effect of small incentives and supply improvement when they are correctly implemented, we need to know whether and how such an incentive programme could be generalised. Under the National Rural Health Mission, the government of India now has a health worker in each village who is responsible for encouraging uptake of preventive care. Furthermore, several Indian states, including those with comparatively low immunisation rates (Orissa, Bihar, Rajasthan), are already implementing a "camp" approach, where the regular auxiliary nurse midwife immunises children in villages on a rotating schedule. We are hoping to conduct an impact evaluation of the addition of small incentives to parents in this structure, in collaboration with the state government in India, to evaluate the potential of these types of intervention to be adopted as large scale policies and the challenges that would need to be overcome.

We thank Jennifer Tobin for her help in editing this manuscript for publication. She was funded by the Abdul Latif Jameel Poverty Action lab. Contributors: AVB, ED, and RG participated in the study design. ED and DK completed the data analysis. All authors participated in data collection, data interpretation, and drafting of the manuscript. ED is guarantor. Funding: This study was funded by the Mac Arthur Foundation. All researchers declare that the research was entirely independent from the funders. The funders had no involvement in the design and conduct of the study; collection, management, analysis, and interpretation of the data; and preparation, review, or approval of the manuscript. The intervention was funded by the Evangelischer Entwicklungdienst (Germany), Inter Church Cooperation for Development Cooperation (Netherlands), and Plan International, through Seva Mandir comprehensive plan. None of the funding organisations participated in the design of the study (although the MacArthur Foundation reviewed the design before making the funding decision), the data collection or analysis, or the decision to submit the paper for publication.

Competing interests: All authors have completed the Unified Competing Interest form at www.icmje.org/coi_disclosure.pdf (available on request from the corresponding author) and declare that they have no competing interests relevant to this work.

Ethical approval: This study was approved by the health ministry of the government of Rajasthan, the office on the use of human subjects at Massachusetts Institute of Technology, and the ethics committee of Vidhya Bhawan, the university which hosted the project in Udaipur. Informed consent was first obtained orally at the community level from the research villages through village meetings to which all adult member of the village were invited. Individual level informed consent was then obtained orally from every family participating in the study. Data sharing: Statistical code and full dataset available from the corresponding author at eduflo@mit.edu. Consent was not obtained, but the presented data are anonymised and risk of identification is extremely low.

1 WHO and UNICEF. Global immunization vision and strategy. World Health Organization, 2005. www.who.int/vaccines-documents/ DocsPDF05/GIVS Final EN.pdf.

2 Bloom D, Canning D, Weston M. The value of vaccination. World Economics 2005;6:15-39.

3 WHO and UNICEF. Global immunization data. World Health Organization, 2008. www.who.int/immunization/newsroom/ Global_Immunization_Data.pdf.

4 Lim SS, Stein DB, Charrow A, Murray Cl. Tracking progress towards universal childhood immunisation and the impact of global initiatives: a systematic analysis of three-dose diphtheria, tetanus, and pertussis immunisation coverage. Lancet 2008;372:2031-46.

5 Coutinho L, Bisht S, Raje G. Numerical narratives and documentary practices: vaccines, targets and reports of immunisation programme. Econ Polit Wkly 2000;35:656-66.

6 National Family Health Survey, 2005-2006 (NHFS-3). www.nfhsindia. org/pdf/RJ.pdf. 
7 Grabowski M, Farrell N, Hawley W, Chimumbwa J, Nobiya T, Ahun M, et al. Ghana and Zambia: achieving equity in the distribution of insecticide-treated bednets through links with measles vaccination campaigns. Health, nutrition, and population (HNP) discussion paper. World Bank, 2005.

8 Wiysonge CS, Nomo E, Mawo JNN, Ticha JM. Accelerated measles control in sub-Saharan Africa. Lancet 2006;367:394-5.

9 Loevinsohn BP, Loevinsohn ME. Well child clinics and mass vaccination campaigns: an evaluation of strategies for improving the coverage of primary health care in a developing country. Am J Public Health. 1987;77:1407-11.

10 Rivera JA, Sotres-Alvarez D, Habicht JP, Shamah T, Villalpando S. Impact of the Mexican program for education, health, and nutrition (Progresa) on rates of growth and anemia in infants and young children: a randomized effectiveness study. JAMA 2004:291:2563-70.

11 Lagarde M, Haines A, Palmer N. Conditional cash transfers for improving uptake of health interventions in low- and middle-income countries: a systematic review. JAMA 2007;298:1900-10.

12 Fernald LCH, Gertler PJ, Neufeld LM. Role of cash in conditional cash transfer programmes for child health, growth, and development: an analysis of Mexico's Oportunidades. Lancet 2008;371:828-37.

13 Glassman A, Todd J, Gaarder M. Latin America: cash transfers to support better household decisions. In: Eichler R, Levine R, eds. Performance-based incentives working group. performance incentives for global health: potential and pitfalls. Brookings Institution Press, 2009:89-121.

14 Maluccio J, Flores R. Impact evaluation of a conditional cash transfer program: the Nicaraguan Red de Proteccion Social. Food Consumption and Nutrition Division (FCND) Discussion Paper No 184. International Food Policy Research Institute, 2004.

15 Banerjee A, Deaton A, Duflo E. Health care delivery in rural Rajasthan. Econ Polit Wkly 2004;39:944-9.

16 WHO. Selected vaccine introduction status into routine immunization. World Health Organization, 2003. www.who.int/ immunization_monitoring/routine/schedule_analysis_2003.pdf.
17 Nichter M. Vaccinations in the third world: a consideration of community demand. Soc Sci Med 1995;41:617-32

18 Atkinson W, Pickering L, Schwartz B, Weniger B, Iskander J, Watson J. General recommendations on immunization. MMWR Recomm Rep 2002;51:1-36.

19 Thornton R. The demand for and impact of learning HIV status: Evidence from a field experiment. Am Econ Rev 2008;98:1829-63.

20 Filmer D, Schady N. Are there diminishing returns to transfer size in conditional cash transfers? Policy Research Working Paper Series 4999. World Bank, 2009.

21 Kremer M, Miguel E. The illusion of sustainability. QJ Econ 2007;122:1007-65.

22 Cohen J, Dupas P. Free distribution or cost-sharing? Evidence from a randomized malaria prevention experiment. Brookings Global Economy and Development Working Paper No 11. Brookings Institute, 2007.

23 Morris SS, Flores F, Olinto P, Medina JM. Monetary incentives in primary health care and effects on use and coverage of preventive health care interventions in rural Honduras: cluster randomized trial. Lancet 2004;364:2030-7.

24 Martins N, Morris P, Kelly PM. Food incentives to improve completion of tuberculosis treatment: randomised controlled trial in Dili, TimorLeste. BMJ 2009;339:b4248.

25 Health Budget 2006-07: new directions? Express Healthcare Management 2006;April. www.expresshealthcaremgmt.com/200604/ budgetanalysis01.shtml

26 Shea B, Neil A, David H. Increasing the demand for childhood vaccination in developing countries: a systematic review. BMC Int Health Hum Rights 2009;9(suppl I):S5.

27 Travis P, Bennet S, Haines A, Pang T, Bhutta Z, Hyder AA, et al. Overcoming health systems constraints to achieve the Millennium Development Goals. Lancet 2004;364:900-6.

Accepted: 11 April 2010 